\title{
EL PUNTO DE VISTA EN "LA TEJEDORA DE PALABRAS" DE RIMA DE VALLBONA
}

\author{
Julia G. Cruz
}

\begin{abstract}
RESUMEN
Este trabajo versa sobre el trato "mágico" que Rima de Vallbona le da al tema de Circe del antiguo mito homérico en su cuento "La tejedora de palabras", que aparece en su libro Los infiernos de la mujer y algo más... Al retomar el tema de Circe, Vallbona le da una nueva estructura dentro de un contexto contemporáneo, el del mundo académico, del cual participa mucha de la crítica de hoy en día. Es a través del lenguaje que Vallbona logra crear un ámbito verosímil para el lector y los personajes del cuento pero que repentinamente se transforma en "otro", el de la fantasía o pesadilla o, tal vez, la realidad que uno preferiría evadir.
\end{abstract}

\begin{abstract}
The following article discusses the magical treatment that Rima de Vallbona gives to Circe, one of Homer's mythological characters, in "La tejedora de palabras". In this short story, from the book Los infiernos de la mujer y algo más... Vallbona gives the character a new structure within a contemporary academic context. Through language, Vallbona creates a new environment for the characters and the reader. However, this environment is suddendly tranformed into fantasy, nightmare or possibly a denied reality.
\end{abstract}

Rima de Vallbona nos presenta el mágico retrato de su Circe en el relato fantástico "La tejedora de palabras" a través de la mirada de Rodrigo, el protagonista, con la siguiente descripción:

El violento fulgor veraniego de los ocasos de Houston estalló en mil resplandores rojizos en su hermosa cabellera, la cual lo dejó deslumbrado por unos momentos; era como si hubiese entrado en una zona mágica en la que ni el tiempo, ni los sentidos, ni la realidad tuvieran cabida alguna. Ella se dirigía hacia el edificio de lenguas clásicas y modernas cuando Rodrigo tuvo la fugaz visión suya de espaldas, aureolada por el brillo de una nunca antes vista frondosa mata de pelo. Iba cantando -o eso le pareció a él-, con una // voz tan melodiosa, que por unos instantes se suspendieron sus sentidos y quedó petrificado (Vallbona 1992: 11-2).

La descripción de la bellísima mujer podría considerarse como verosímil; sin embargo, cuando ella se vuelve repentinamente hacia el protagonista, se presencia una increíble, horripilante metamorfosis: 
(...) se le manifestó de pronto como un ser grotesco: ... [su cabellera] se trocó en un marchito pelaje color rata muerta, grasienta, sucia. Lo que más le impresionó es que pese a la distancia que lo separaba de ella, le llegó a él un intenso y repugnante olor a soledad, a total abandono, como de rincón que nunca se ha barrido ni fregado. (Vallbona 1992: 12).

En la literatura fantástica tradicional, es a esto a lo que suele llamársele la irrupción de lo insólito. Según el teórico Todorov, "lo fantástico se define como una percepción particular de acontecimientos extraños" (1972: 111) y, además, "produce un efecto particular sobre el lector (...)" (1972: 112). El teórico sugiere horror, asco, sorpresa, o simplemente curiosidad y la narradora del relato indica en concreto: "náuseas, lástima, miedo (...)” (Vallbona 1992: 12).

En la creación del universo fantástico, el único vínculo con la realidad que se mantiene es el que el lenguaje le otorga y nada más: “(...) la descripción y lo descrito no tienen una naturaleza diferente (Todorov 1972: 92)". En "La tejedora de palabras", Vallbona crea tal mundo a través del lenguaje -de las palabras- como su Circe, la tejedora de palabras de este relato. Se trata, principal aunque no exclusivamente, de una descripción verosímil, salvo en cuanto al acontecimiento de lo insólito, según lo que percibe su joven protagonista, Rodrigo.

Desde el primerísimo párrafo del cuento, "La tejedora de palabras", se le presenta al lector a la Circe de Vallbona a través de la mirada de Rodrigo. La impresión experimentada por los ojos y los oídos del protagonista se le comunica al lector por medio de la descripción lingüística de la narradora. Había sido una mirada rápida, no obstante "mágica", de su espalda y su cabellera rojiza, brillante. Rodrigo tuvo la impresión de que ella cantaba con una voz melodiosa y que subía la escalera majestuosamente. Él había quedado boquiabierto, tal como su amiga Eva había observado. Esta identificó a la mujer, a quien Rodrigo y el lector habían percibido como de una belleza imponente, como la profesora Thompson, cuyo curso en lenguas clásicas acababa él de matricular. Justo el día anterior, Eva le había estado hablando de ella. En ese momento, la profesora abrió la puerta del edificio y repentinamente se volvió hacia él dándole una mirada ardiente con la cual la bella imagen se transformó en una grotesca que le causó "náusea, lástima, temor (...)" (Vallbona 1992: 12) a Rodrigo. El pobre estudiante no podía creer lo que acababa de transcurrir ante sus mismos ojos ni las categóricas aseveraciones de Eva de que esta "bag lady" sería verdaderamente su profesora:

Verás las sorpresas que te guardan sus clases, Rodrigo-. Muerta de risa, Eva se alejó hacia el edificio de filosofía mientras le recomendaba andarse con cautela con la profesora Thompson porque ..., ¡a saber por qué!, pues la últimas palabras las borró en el aire el traqueteo del camión que pasaba en ese momento recogiendo la basura (Vallbona 1992: 13).

Este elemento de prefiguración insinúa mayor desarrollo del elemento insólito en este relato. La teoría de lo fantástico de Todorov ha propuesto el planteamiento de un mundo verosímil, que el lector reconoce como el suyo, como una de sus condiciones más importantes para producir el ambiente de este modo literario (o género, como le llama Todorov). Para propiciar lo fantástico, tan solo hace falta la infracción de ese orden; esto se logra con la intromisión de lo insólito en ese mundo conocido por el lector. El escenario del cuento "La tejedora de palabras" de Vallbona es, para el lector, un mundo identificable, el mundo académico, contemporáneo. Hasta 
este punto, solo el protagonista y el lector han sido testigos del único prodigio en el relato. El lector ha sido testigo ocular a través de la mirada de Rodrigo y gracias a la descripción de la narradora. Eva no tuvo la misma imagen de la profesora Thompson. Eva había oído hablar de ella; pero como le cuenta burlonamente esos chismes a Rodrigo, se nota que ella no los ha tomado muy en serio. Por lo tanto, se podría decir que Eva pertenece perfectamente a esa realidad empírica que representa el mundo académico, dentro y fuera del texto literario.

No obstante, la narradora omnisciente de Vallbona reintegra al lector a ese estado de perfecto equilibrio entre la realidad y lo imaginario que representa la ambigüedad de lo fantástico puro:

Como si la profesora Thompson adivinara que hablaban de ella, en un instante fugaz la divisó Rodrigo mirándolo con fijeza detrás de los cristales tornasolados de la puerta... lo cierto es que cayó de nuevo presa del embrujo de la primera visión de ella: se le volvió a manifestar en todo el esplendor de su abundante y hermosa cabellera orlada de fulgores mágicos que le daban una aureola de diosa, como salida de un extraño mundo de fantasías (Vallbona 1992: 13).

Desde ese momento en adelante, Rodrigo permanecerá en un constante vaivén de imágenes alternadas de la profesora Thompson, en todo lugar y a todas horas: Ahora será la "bag lady", ahora la pelirroja hechicera; ... frecuentemente pensando en darse de baja en el curso de literatura homérica pero permaneciendo siempre en vilo.

Aunque los compañeros de clase de Rodrigo se burlan del aspecto de ella, todos reconocen que sus clases son fascinantes, como pocas de otros profesores. Rodrigo siente que la profesora Thompson le dedica cada clase a él; que ella está tejiendo una manta divina de palabras exclusivamente para él. Toda esa fantasía halaga a Rodrigo y lo seduce.

Consciente del efecto de sus palabras, la Circe de Vallbona, al entretejer las aventuras homéricas, sabe que lo está llevando a ese mundo heroico de antaño e intuye que está arropándolo con su "manta divina". Ella sabe cómo conmover su amor: como Ulises, él es un hombre por encima de todos los demás. Como muestra de reconocimiento, la profesora le escribe comentarios sobre su persona con palabras halagadoras en los trabajos para el curso y culmina la seducción invitando a Rodrigo a vivir con ella y con sus muchos gatos. La profesora Thompson le da a su alumno la llave de su casa, con un mapa de cómo llegar a ella, y, para calmarle sus inquietudes, lo anima diciéndole:

Te sobran razones para creer que lo que ves, percibes, piensas, sientes, es equivocado. Sin embargo, nada de eso es equivocado, sólo diferente a lo que los demás ven, perciben, piensan y sienten. Debes tener más fe en ti mismo, Rodrigo, muchachote de mi alma. (Vallbona 1992: 17).

Un día Rodrigo camina con su profesora hasta el automóvil de ella. Como el suyo está estacionado mucho más lejos, ella ofrece llevarlo hasta allá. En el momento que él entra en el automóvil, le da náuseas "el violento tufo de orines y excrementos de gatos". Rodrigo ve que dos de los muchísimos gatos de la profesora están en el automóvil. Lo miran "con odio y rabia (al menos así le pareció a él cuando atrapaba en la oscuridad el oro luminoso de sus pupilas felinas...)" (Vallbona 1992: 19). 
Allí, en el automóvil, la profesora Thompson se transforma una vez más en la bella y encantadora Circe. Rodrigo sabe que al fin ha quedado total y perpetuamente envuelto en la red divina tejida de las palabras.

El cuento tiene un epílogo en el cual, Claudia, otra alumna de la profesora Thompson en la clase sobre Homero, le pregunta que si ya sabe que Rodrigo Carrillo ha estado desaparecido "desde el jueves pasado". La profesora le contesta que no había sabido nada pero que confía en que, esté donde esté, Rodrigo no peligra en lo absoluto. Ella continúa con su conferencia sobre otra aventura de Ulises, la de Circe, la cantante de bellísima voz y la tejedora de la manta divina. En ese momento, Héctor, otro estudiante, se fija en la profesora Thompson. La increíblemente bellísima pelirroja que ve ante sus ojos no tiene ninguna semejanza con su profesora, esa mujer alta, gruesa, vieja y desaliñada de una mirada dura y amargada. La profesora Thompson, con voz melodiosa en lugar de su acostumbrada voz fuerte y ronca, sigue adelante su conferencia sobre cómo Circe tornó en cerdos a la tripulación de Ulises.

A lo largo de la historia, el lector puede llegar a concluir que la percepción de Rodrigo de la metamorfosis de su profesora ocurre sólo en la imaginación del protagonista. El lector podría atribuir estas "alucinaciones" a alguna explicación racional, como por ejemplo, que Rodrigo podría estar a punto de sufrir una crisis nerviosa, o tal vez anda bajo la influencia de drogas, etc. Sin embargo, no hay nada en el relato que sustente tales posibilidades y la narradora omnisciente elimina toda explicación racional al presentarnos a Héctor, el otro estudiante y testigo del mismo acontecimiento insólito, hacia el final del relato. Él tiene la misma visión de la Circe, la metamorfosis de la profesora Thompson. Este estado que suele resultar "evanescente" en la literatura fantástica tradicional, en "La tejedora de palabras" de Vallbona se sostiene en equilibrio perfecto entre la explicación racional y la sobrenatural, más allá de la extensión de la lectura del texto. Por lo tanto, este caso sería uno que Todorov categorizaría de lo fantástico puro.

Todorov tiene razón al certificar que lo fantástico sólo se logra a través del lenguaje. Vallbona, también, es una verdadera tejedora de palabras; por medio del lenguaje ella le ha porporcionado al lector la perspectiva del protagonista: La perspectiva mágica de los acontecimientos que irrevocablemente acaban transformando la vida del protagonista. Vallbona ha empleado diversos artificios, todos relacionados con aspectos verbales y sintácticos del discurso literario.

Según el trato de la perspectiva que se cultiva en "La tejedora de palabras", la narradora omnisciente le permite al lector ver con los ojos del protagonista lo que la seductora, la profesora Thompson, con su magia, le hace ver. Se describe en detalle el aspecto visual de la profesora en su insólita transformación desde la perspectiva de Rodrigo (y después, también, desde la de Héctor: el mismo prodigio se le manifiesta). Es decir, el lector adquiere otra función más en el relato. Se convierte, además, en calidad de testigo ocular, en cómplice del protagonista. Cuando el lector "presencia" como Rodrigo, la transformación de aquella "maga", el lector implícito del texto comparte también el papel de testigo ocular. Es decir, el lector "presencia" lo mismo que el protagonista "presencia" antes, durante y después de la metamorfosis. Dentro del mundo del texto literario, tales transformaciones sobrenaturales pueden ocurrir. Pero este aspecto visual pertenece al contexto del orden establecido, el mundo real que el lector conoce como el suyo. Entonces, en "La tejedora" el elemento insólito, la metamorfosis, resulta ser "el anzuelo" que atrae la atención del joven y sirve para reforzar esa misma atracción. Pero lo que verdaderamente seduce por completo 
a Rodrigo es la conquista del amor propio. Esto lo logra la Circe de Vallbona con el "manto divino" de sus palabras, con las cuales enreda paulatinamente al protagonista.

La teoría literaria le ha prestado gran atención al aspecto de la perspectiva de la narración. Dentro de estos estudios se ha tenido que reconocer la función del narrador implícito al texto y desde luego el personaje receptor de la descripción. Esta función también conlleva una relación con el lector implícito al texto. Estas relaciones entre las respectivas funciones del lector, narrador y personaje(s) se manifiestan en diferentes niveles/grados y con sus respectivas variantes. No se tratarán aquí tales relaciones puesto que eso representaría un trabajo más extenso del que aquí se pretende hacer. Solo se pueden indicar las funciones que este texto incluye. Por ejemplo, como ya hemos establecido que "La tejedora de palabras" es un relato de lo fantástico puro, podemos señalar que, en lo que se refiere al texto de la expresión fantástica, es la descripción lo que destaca la imagen de lo insólito, lo cual le permite al lector compartir esa misma experiencia con el agente "focalizador" como le llaman Genette y otros teóricos. En este caso, el "percibidor" o el agente "focalizador" es Rodrigo, el protagonista. Dentro del mundo del texto, desde el principio hasta casi el final, el único personaje representado que percibe las metamorfosis insólitas de la profesora Thompson es Rodrigo (y, a través de su mirada, el lector es su testigo "ocular"). El prodigio ocurre en dos niveles de la "realidad": ante la vista de Rodrigo y en la mente del lector cuando transforma las palabras de la narradora del relato en imágenes mentales. Por eso ha dicho Ziolkowski que:

(...) la experiencia de lo fantástico ocurre en la mente. (...) Es sólo en la mente que podemos saborear ese momento de ambivalencia o incertidumbre, y el modo literario cuya acción ocurre sólo en la mente es la ficción narrativa (Ziolkowski 1977: 250. Traducción mía).

Vallbona ha utilizado bien el punto de vista como artificio literario en ese tapiz lingüístico que da la perspectiva mágica de su Circe en "La tejedora de palabras". Los formalistas rusos incorporaron a esta técnica, excelente para la descripción, la de la llamada "ostranenie", es decir, la desfamiliarización. Su definición es la siguiente:

La representación (...) [la cual] puede compararse al principio de la descripción psicológica desde un punto de vista externo, con el uso de palabras desfamiliarizadoras ('como si', 'según parece' y etc.) La descripción en este caso puede decirse ser subjetiva -es decir, se refiere a uno u otro punto de vista subjetivo (...) (Upensky 1973: 168. Traducción mía.)

Todorov también señala este artificio literario. Dice que el elemento fantástico puede estar precedido "por una serie de comparaciones, de expresiones figuradas o simplemente idiomáticas, (...) [y que] designan un acontecimiento sobrenatural (...)" (Todorov 1972: 97). En otras palabras, el discurso desfamiliarizador de Vallbona condiciona psicológicamente al lector para la metamorfosis en "La tejedora de palabras".

El primer párrafo de este cuento de Vallbona, que se citó al principio de este trabajo, incluye dos ejemplos de su uso: "Era como si" y el comentario parentético de la narradora "-o eso le pareció a él-". En el cuarto párrafo de la segunda página de "La tejedora de palabras", ante Rodrigo "superpuesta a la imagen de la criatura divina, se le manifestó de pronto un ser 
grotesco". El tercer párrafo de la tercera página del cuento, que también se citó anteriormente en la página tres de este trabajo, empieza con la frase "Como si la profesora Thompson (...)". Otros ejemplos de este tipo y otros semejantes pueden encontrarse a través de la extensión del relato.

La selección de verbos y frases que realiza Vallbona son conducentes al mundo conocido aunque mágico de "La tejedora de palabras". A lo largo del cuento, el lector encuentra el modo subjuntivo en los verbos como vehículo gramatical para expresar la irrealidad. El tiempo verbal del copretérito indicativo se ha destacado como el que mejor se presta para la expresión de modo literario de lo fantástico. También puede encontrarse por todo este cuento. Aunque Vallbona utiliza mucho el diálogo, el cual exige sobretodo el uso de los tiempos verbales del presente y del pretérito indicativos; es en la descripción y en la narración donde ella crea esa perspectiva mágica. Es también allí donde se distingue que su tiempo verbal preferido para crearla corresponde al copretérito indicativo, forma que coincide con la que la teoría literaria ha identificado como la que mejor expresa lo fantástico. Vallbona sabe aprovechar bien los aspectos semánticos: figuras y frases como la hipérbole: "mil rayos rojos:", "una zona mágica", "petrificado", "fantasma o alma del más allá", "un laberinto de muerte", "un espantapájaros con la figura de limosnera", "una diosa aureolada", "como si emergiera de un extraño mundo de fantasías", "doble aspecto", "fenómeno", "doble obsesión quimérica", "misteriosa fuerza", "extravagantes espejismos", y verbos y frases de percepción como: "encandilado, parecía, visto, fijó una mirada de cenizas con ascuas, no pudo dar crédito a sus ojos, mostró, mirándolo fijamente, apareciéndosele, percibir, observó, etc.".

El lector implícito se convierte en cómplice de la narradora omnisciente y del protagonista de "La tejedora de palabras" al someterse al requisito de la ficción de "la suspensión de la incredulidad". Dentro del contexto de esta relación, el lector está al tanto no sólo de la experiencia visual del protagonista ante su profesora sino también de lo relatado por la narradora omnisciente. A esto último se le llama prolepsis; en otras palabras, le facilita la información explícita y declarada al lector pero no necesariamente se la entrega al protagonista.

Sin embargo, el trato de la perspectiva por parte de Vallbona en "La tejedora de palabras" es mucho más sofisticado que su uso de la técnica de prolepsis. Desde el principio del relato, parece haber puntos temporales dobles en la aparente perspectiva presentada. Esta es una forma complicada de focalización, como le llama Genette, pero no de definición. La perspectiva en "La tejedora de palabras" es una en la cual se hace la descripción desde dos puntos temporales:

La narrativa que resulta no es una yuxtaposición de perspectivas sino una síntesis en la cual diferentes puntos de vista temporales se fusionan, (...) de manera que la descripción aparece, como quien dice, como un especie de doble fotografía (Upensky 1973: 67. Traducción mía.).

La combinación de perspectivas temporales en el cuento de Vallbona se manifiesta en la forma de los comentarios de la narradora omnisciente intercalados, en la narración, con las palabras del propio Rodrigo en el diálogo acerca de lo insólito. La perspectiva inyectada de la narradora "sirve de trasfondo sobre el cual el relato en secuencia de los acontecimientos se percibe" (Upensky 1973: 67. Traducción mía). Como se indicó arriba, la doble 
perspectiva es el resultado de la función de la narradora omnisciente: ella sabe lo que el protagonista no sabe. Su perspectiva está "sincronizada con la del personaje, como si hubiera adoptado su 'tiempo del presente"'. Tanto la narradora como el protagonista están en el mismo tiempo interno del nivel temporal narrativo. Es la narradora quien le comunica al lector implícito lo que Rodrigo ve. Por otra parte, el personaje tiene conocimiento limitado. El sabe y experimenta solo lo que la narradora le permite.

Por último, la narradora también está en un tiempo externo al plano temporal narrativo, es decir, en "La tejedora de palabras", la narradora, en calidad de ser omnisciente, podría develarle al lector lo que está deparado para Rodrigo en el futuro. Puesto que la narradora:

Está fuera de sus personajes, (...) dentro de su propio tiempo, ella adopta una mirada retrospectiva, mirando desde el futuro hacia atrás que es el presente de su personaje. (...) su perspectiva es externa ante la narración en marcha (Upensky 1973: 67).

Indudablemente, Rima de Vallbona con habilidad ha logrado establecer un vínculo entre la narradora y el lector al crear una perspectiva mágica de su Circe para su protagonista Rodrigo, y después para Héctor, en su impresionante cuento de lo fantástico puro, "La tejedora de palabras".

\section{Bibliografía}

Bal, Mieke. 1977. "Narration et focalisation". Poétique. 29: 107-27.

Brooke-Rose, Christine. 1981. A Rhetoric of the Unreal. Cambridge: Universidad de Cambridge.

Genette, Gérard. 1972. Figures III. París: Seuil.

Lanser, S. S. 1981. The Narrative Act. Princeton: Universidad de Princeton.

Martin, Wallace. 1986. Recent Theories of Narrative. Ithaca: Universidad de Cornell.

Todorov, Tzvetan. 1972. Introducción a la literatura fantástica. Buenos Aires: Tiempo Contemporáneo.

1981. Introduction to Poetics. Minneapolis: Universidad de Minnesota.

Upensky, Boris. 1973. A Poetics of Composition. Berkely: Universidad de California.

Vallbona, Rima de. 1992. Los infiernos de la mujer y algo más. Madrid: Torremozas.

Ziolkowski, Theodore. 1977. Disenchanted Images. Princeton: Universidad de Princeton. 
